\title{
Study on the Combustion Characteristics and Kinetic Parameters of the Blended Coal Treated with Different Grinding Methods
}

\author{
Wang Boping ${ }^{1, *}$, Liu Liang ${ }^{1}$, Wang Xun ${ }^{1}$, Fang Xunzhou ${ }^{2}$, Hou Qinjia ${ }^{1}$, Liu Zenghui ${ }^{1,}$ Wang Kailun ${ }^{1}$ \\ ${ }^{1}$ School of energy and power engineering, Changsha University of Science and Technology,Changsha,410114,China \\ ${ }^{2}$ Huadian Fuxin Guangzhou Energy Co., Ltd., Guangzhou, 100031, China \\ * Corresponding author: Wang Boping (1994 -), School of energy and power engineering, Changsha University of Science and \\ Technology.
}

\begin{abstract}
The presented investigation focused on the combustion characteristics and kinetic parameters of the coals blended using different grinding methods (separated and mixed grinding), via Thermogravimetric analyser. According to the thermogravimetric experiments, with the increase of the proportion of Yangcheng coal, the combustion characteristics of the coal treated with the mixed grinding method are increasingly better than those of the coal treated with the separated grinding method (under the same mixing ratio). Additionally, the methods of Coats-Redfern were applied to calculate kinetic parameters, which indicated that when the proportion of Yangcheng coal is $30 \%$, the activation energy values of the coal treated with two grinding methods are similar; when the proportion of Yangcheng coal is below 30\%, the activation energy values of coal treated with the separated grinding method is lower than that of the coal treated with the mixed grinding method; when the proportion of Yangcheng coal is above 30\%, the activation energy values of the coal treated with the mixed grinding method is lower than that of the coal treated with the separated grinding method.
\end{abstract}

\section{Introduction}

The diversity of coal quality is a major issue in thermal power stations at the current stage. To ensure the stable and economical operation of pulverized coal furnaces, power coal blending is often used to satisfy the needs of boilers at power stations. Many domestic scholars have studied coal blending techniques. For example, Cao ${ }^{[1]}$ used a thermogravimetric analyzer to study the combustion characteristics, $\mathrm{NO}_{\mathrm{x}}$ emission laws, and slagging conditions of Mongolian coal and its blended coal by means of separated grinding and blending combustion. $\mathrm{Fu}^{[2]}$ et al. carried out optimization research on coal blending for coal-fired power stations, which can provide guidance for related operations. $\mathrm{Wu}{ }^{[3]}$ et al. studied the influence of different pyrolysis temperatures and rates on the combustion characteristics of the semicoke jetted by blast furnace by adopting the thermogravimetric analysis method. Xia ${ }^{[4]}$ et al. established an optimized practical coal miller combination model so as to improve the coal blending decision-making system for a coal-fired power plant. Zhang et al. ${ }^{[5]}$ found that when the proportion of easily grindable coal reached about $40 \%$, the Hardgrove grindability index (HGI) of the blended coal increased significantly. $\mathrm{Ma}{ }^{[6]}$ et al. found that for out-of-furnace blending combustion, lower proportion of bituminous coal could lead to greater promotion effect between the blended coals, thus improving the burnout rate; with the increase of this proportion, the suppression effect would be gradually strengthened, which is not conducive to the burnout of the blended coal.

Researchers at home and abroad have conducted a series of studies on blending combustion and models of the blended coal as well as the characteristics of particle composition ${ }^{[7-8]}$ and combustion. Compared with raw coal, the blended coal changes significantly after blending, so simple superposition cannot help to accurately predict the combustion characteristics of the blended coal sample. This paper conducts thermogravimetric experiments by taking the blended coal with different proportions as the material and by adopting the two methods of mixed coal grinding (mix coal before grinding) and separated coal grinding (mix coal after grinding). This paper explores the influence of blending methods on the combustion characteristics and kinetic parameters of the blended coal, aiming to find a suitable method for coal blending.

\section{Experiment}

\subsection{Sample preparation}

This experiment adopts the 5E-MAC3 industrial analyzer and the NETZSCH STA449 thermal analyzer (TG) and takes two commonly used coals (anthracite in Yangcheng, Shanxi Province and bitumits in Zhengzhou, Henan Province) as the materials. Untreated raw coal briquettes 
taken before the experiment were ground into qualified coal powder according to the experimental needs.

We adopted two methods of mixed grinding and separated grinding to prepare 10 blended coal samples $(1: 9,3: 7,5: 5,7: 3,9: 1)$, plus two unblended coal samples (a total of 12 samples). For the sake of convenience, we numbered them in sequence as $\# 1, \# 2, \# 3, \# 4, \# 5, \# 6, \# 7$, $\# 8, \# 9, \# 10$, \#A, \#E (see Table 1). The industrial analysis of coal is shown in Table 2 .

Table 1 Sample number

\begin{tabular}{|c|c|}
\hline Samples & Number \\
\hline Mixed grinding A:E=1:9 & $\# 1$ \\
\hline Mixed grinding A:E=3:7 & $\# 2$ \\
\hline Mixed grinding A: $\mathrm{E}=5: 5$ & $\# 3$ \\
\hline Mixed grinding A:E=7:3 & $\# 4$ \\
\hline Mixed grinding A: $\mathrm{E}=9: 1$ & $\# 5$ \\
\hline Separate grinding A:E=3:7 & $\# 7$ \\
\hline Separate grinding A: $\mathrm{E}=5: 5$ & $\# 8$ \\
\hline Separate grinding A: $\mathrm{E}=7: 3$ & $\# 9$ \\
\hline Separate grinding A:E$=9: 1$ & $\# 10$ \\
\hline $\mathrm{A}$ & $\# \mathrm{~A}$ \\
\hline $\mathrm{E}$ & $\# \mathrm{E}$ \\
\hline
\end{tabular}

Table 2 Industrial analysis of samples

\begin{tabular}{|c|c|c|c|c|}
\hline Number & $\mathrm{Mad}$ & $\mathrm{Aad}$ & $\mathrm{Vad}$ & $\mathrm{FCad}$ \\
\hline$\# 1$ & 0.89 & 28.87 & 18.43 & 51.81 \\
\hline$\# 2$ & 1.81 & 16.24 & 13.93 & 68.02 \\
\hline$\# 3$ & 2.82 & 17.02 & 6.14 & 74.02 \\
\hline$\# 4$ & 1.83 & 23.64 & 9.57 & 64.96 \\
\hline$\# 5$ & 1.85 & 33.02 & 16.12 & 49.01 \\
\hline$\# 6$ & 1.12 & 16.32 & 16.34 & 66.22 \\
\hline$\# 7$ & 1.78 & 8.94 & 10.81 & 78.47 \\
\hline$\# 8$ & 1.87 & 18.79 & 6.45 & 72.89 \\
\hline$\# 9$ & 1.78 & 27.42 & 12.26 & 58.54 \\
\hline$\# 10$ & 1.84 & 36.41 & 18.74 & 43.01 \\
\hline$\# \mathrm{~A}$ & 2.5 & 22.02 & 10.99 & 64.49 \\
\hline$\# \mathrm{E}$ & 1.92 & 38.59 & 19.86 & 39.63 \\
\hline
\end{tabular}

\subsection{Conditions of thermogravimetric experiment}

Sample mass: $10.0 \mathrm{mg} \pm 0.5 \mathrm{mg}$;

Heating rate: $20^{\circ} \mathrm{C} / \mathrm{min}$;

Temperature range: $25^{\circ} \mathrm{C}<\mathrm{T}<1000^{\circ} \mathrm{C}$;

Experimental atmosphere: air;

Air flow: $100 \mathrm{~mL} / \mathrm{min}$.

\subsection{Evaluation index of combustion performance}

Ignition temperature $\mathrm{T}_{\mathrm{i}}$ : obtained by TG-DTG method (as shown in Figure 1);

Burnout temperature $\mathrm{T}_{\mathrm{f}}$ :the temperature when the weight loss rate of the TG curve exceeds $98 \%$;
Maximum burning rate $(\mathrm{dw} / \mathrm{dt})$ max;

Peak temperature $\mathrm{T}_{\mathrm{m}}$ : the temperature corresponding to the maximum value of DTG;

Average burning rate (dw/dt) mean;

Comprehensive combustion characteristic index $\mathrm{S}_{\mathrm{N}}$ :

$$
S_{N}=\frac{(d w / d t)_{\max } d w / d t_{\text {mean }}}{T_{i}^{2} T_{f}}
$$

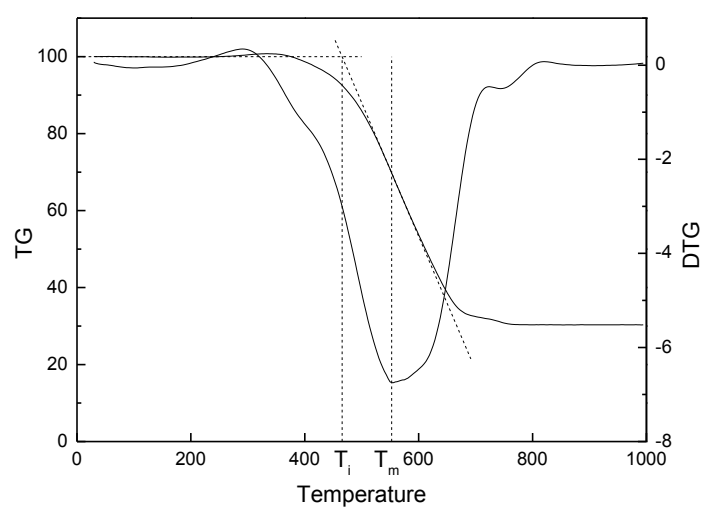

Figure 1 Schematic diagram of ignition temperature

\subsection{Obtaining activation energy values and mechanism functions}

According to Arrhenius Equation ${ }^{[9]}$ and the effective collision theory of chemical reactions, when the activation energy value is lower, the reaction is easier to occur, and vise versa. ${ }^{[10]}$ This paper uses the Coats-Redfern firstorder equation ${ }^{[11]}$ to calculate the kinetic parameters of the coal combustion process $\left(\mathrm{T}_{\mathrm{i}}<\mathrm{T}<\mathrm{T}_{\mathrm{f}}\right)$. The final equation can be expressed as:

$$
\ln \left[\frac{-\ln (1-\alpha)}{T^{2}}\right]=\ln \left(\frac{A R}{\beta E}\right)-\frac{E}{R T}
$$

In the formula:

$\alpha-$ mass conversion rate at time $\mathrm{t}$;

$\alpha=\frac{m_{0}-m_{t}}{m_{0}-m_{\infty}}\left(\mathrm{m}_{0}\right.$ is the initial mass of the sample; $\mathrm{m}_{\mathrm{t}}$ is the sample mass at time $\mathrm{t} ; \mathrm{m}_{\infty}$ is the mass at the final sample temperature);

A_- pre-exponential factor, $1 / \mathrm{min}$;

$\mathrm{E}$ —reaction activation energy values, $\mathrm{kJ} / \mathrm{mol}$;

$\mathrm{R} \longrightarrow$ gas constant, $8.314 \mathrm{~J} /(\mathrm{K} \bullet \mathrm{mol})$;

$\beta$ - heating rate, $\mathrm{K} / \mathrm{min}$;

$\mathrm{T}$ — thermodynamic temperature, $\mathrm{K}$.

Since $\ln \left(\frac{A E}{\beta R}\right)$ in the formula does not change with temperature, $\ln \left[\frac{-\ln (1-\alpha)}{T^{2}}\right]$ and $\frac{1}{T}$ are in the functional relationship of $Y=a X+b\left(\mathrm{Y}=\ln \left[\frac{-\ln (1-\alpha)}{T^{2}}\right], X=\frac{1}{T}\right.$, $\left.a=-\frac{E}{R}, b=\ln \left(\frac{A R}{\beta E}\right)\right)$. The corresponding conversion rate $\alpha$ at any temperature $T$ in any temperature interval can be calculated according to the TG curve, based on which $\mathrm{Y}$ and $\mathrm{X}$ values can also be calculated. The author took multiple $\mathrm{X}$ and $\mathrm{Y}$ points in the combustion area of the 12 samples (the ignition temperature-burnout temperature was selected as the analysis interval) for fitting by adopting the data analysis software and obtained the activation energy values $\mathrm{E}$ and the pre-exponential factor A according to the function expression. ${ }^{[12-14]}$ 


\section{Experimental results and discussion}

\subsection{Analysis of combustion characteristics based on TG-DTG curve}
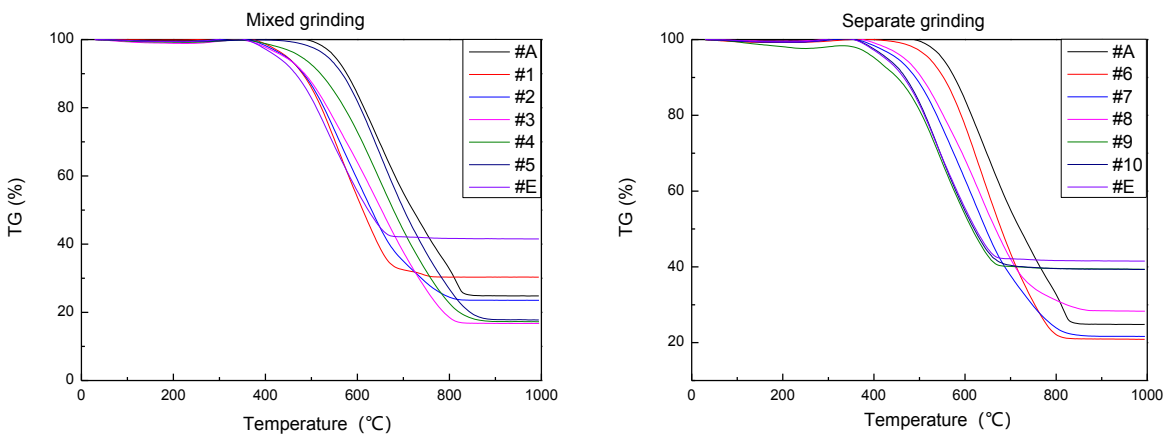

Figure 2 TG-temperature diagram of sample
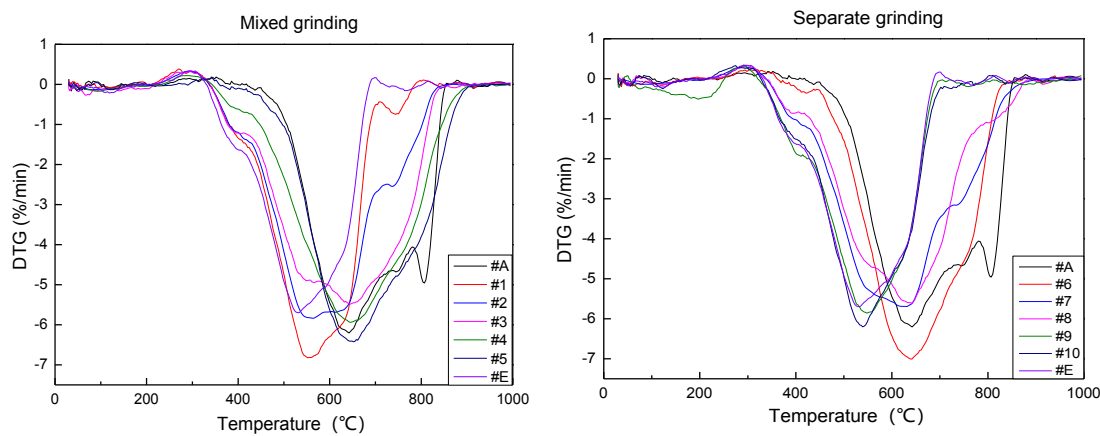

Figure 3 DTG-temperature diagram of sample
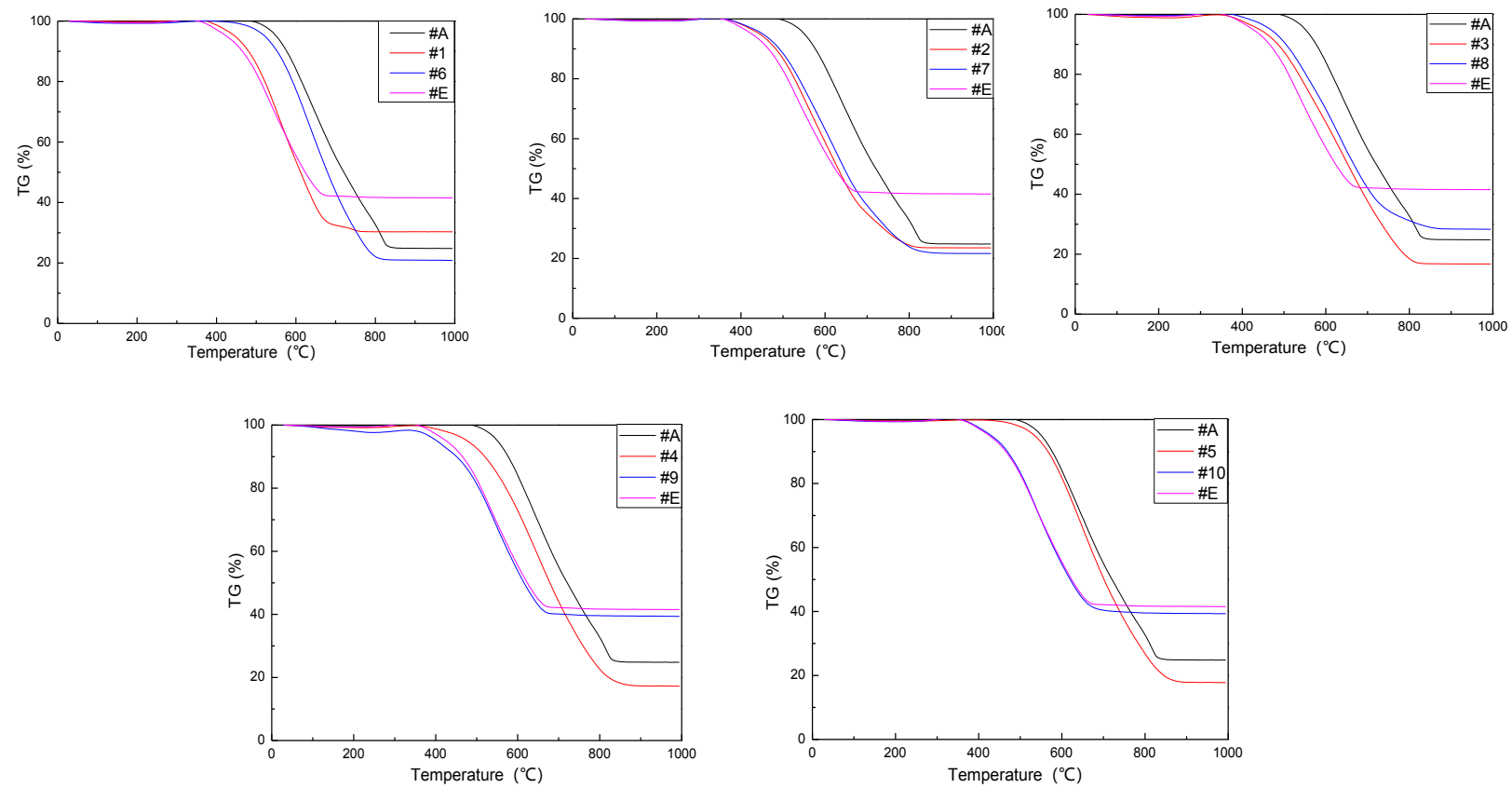

Figure 4 TG-temperature diagram of samples with the same proportion and different grinding methods

Figure 2 to Figure 4 show the thermogravimetric experimental data of 12 coal samples. The overall trends of the TG and DTG curves of the samples are generally similar, and the combustion characteristic temperatures of different samples are not completely consistent. It can be seen from Table 3 that the ignition temperature $T_{i}$, the burnout temperature $T_{f}$, and the peak temperature $T_{m}$ of the 10 blended coal samples are basically within the range 
of the corresponding characteristic temperatures of the two unblended coals.

As shown in Figure 5, the comprehensive combustion characteristic index $S_{N}$ of the blended coal treated with the mixed and the separated grinding methods decreases with the increase of the proportion of Yangcheng coal. $\mathrm{S}_{\mathrm{N}}$ of the blended coal treated with the separated grinding method is basically in a linear relationship with the proportion of Yangcheng coal, while $S_{N}$ of the blended coal treated with the mixed grinding method is not, indicating that the mixed grinding method promotes the complicated internal interaction of the blended coal more significantly ${ }^{[15]}$, which affects the combustion characteristics. When the proportion of Yangcheng coal is $30 \%, \mathrm{~S}_{\mathrm{N}}$ of two grinding methods are similar; when the proportion of Yangcheng coal is lower than $30 \%, \mathrm{~S}_{\mathrm{N}}$ of the blended coal treated with the separated grinding method is higher; when the proportion of Yangcheng coal is higher than $30 \%, \mathrm{~S}_{\mathrm{N}}$ of the blended coal treated with the mixed grinding methods higher. At this time, the Yangcheng coal with a higher hardness has an obvious comminution effect on the Zhengzhou coal with a lower hardness.

Table 3 combustion characteristic parameters of samples

\begin{tabular}{|c|c|c|c|c|c|c|c|c|c|}
\hline Number & $\begin{array}{c}\text { The } \\
\text { proportion } \\
\text { of } \\
\text { Yangcheng } \\
\text { coal (\%) }\end{array}$ & $\begin{array}{c}\text { Ignition } \\
\text { temperature } \\
\mathrm{T}_{\mathrm{i}}\left({ }^{\circ} \mathrm{C}\right)\end{array}$ & $\begin{array}{c}\text { Burnout } \\
\text { temperature } \\
\mathrm{T}_{\mathrm{f}}\left({ }^{\circ} \mathrm{C}\right)\end{array}$ & $\begin{array}{c}\text { Average } \\
\text { burning rate } \\
\mathrm{dw} / \mathrm{d} \tau) \text { mean }\end{array}$ & $\begin{array}{c}\text { Maximum } \\
\text { burning rate } \\
(\mathrm{dw} / \mathrm{d} \tau)_{\max } \\
(\mathrm{mg} / \mathrm{min})\end{array}$ & $\begin{array}{c}\text { Peak } \\
\text { temperature } \\
\operatorname{Tm}\left({ }^{\circ} \mathrm{C}\right)\end{array}$ & $\begin{array}{l}\text { Flammability } \\
\text { index } \mathrm{C}_{\mathrm{b}}\left(\times 10^{-}\right. \\
{ }^{6} \mathrm{mg} /\left(\mathrm{min} \cdot \mathrm{K}^{2}\right)\end{array}$ & $\begin{array}{c}\text { Combustion } \\
\text { stability index G } \\
\left(\times 10^{-6}\right. \\
\mathrm{mg} /\left(\mathrm{min} \cdot \mathrm{K}^{2}\right)\end{array}$ & $\begin{array}{c}\text { Comprehensive } \\
\text { combustion } \\
\text { characteristic } \\
\text { index } \mathrm{S}_{\mathrm{N}} \\
\left(\times 10^{-}\right. \\
{ }^{10} \mathrm{mg}^{2} /\left(\mathrm{min} \cdot \mathrm{K}^{2}\right)\end{array}$ \\
\hline$\# \mathrm{~A}$ & 0 & 440 & 686 & 0.142 & 0.686 & 545.62 & 1.350 & 1.176 & 2.006 \\
\hline$\# 1$ & 10 & 464.765 & 763 & 0.150 & 0.733 & 549.44 & 1.346 & 1.208 & 1.958 \\
\hline$\# 2$ & 30 & 459.52 & 826 & 0.175 & 0.647 & 568.04 & 1.206 & 1.051 & 1.925 \\
\hline$\# 3$ & 50 & 465.53 & 828 & 0.187 & 0.611 & 667.27 & 1.120 & 0.880 & 1.902 \\
\hline$\# 4$ & 70 & 510.61 & 884 & 0.192 & 0.667 & 641.82 & 1.085 & 0.930 & 1.802 \\
\hline$\# 5$ & 90 & 545.66 & 897 & 0.180 & 0.725 & 638.97 & 1.082 & 0.971 & 1.669 \\
\hline$\# 6$ & 10 & 534.775 & 822 & 0.180 & 0.791 & 632.23 & 1.212 & 1.081 & 2.003 \\
\hline$\# 7$ & 30 & 466.23 & 820 & 0.169 & 0.646 & 560.12 & 1.182 & 1.049 & 1.944 \\
\hline$\# 8$ & 50 & 491.38 & 874 & 0.170 & 0.703 & 638.45 & 1.203 & 1.009 & 1.791 \\
\hline$\# 9$ & 70 & 435.96 & 688 & 0.125 & 0.643 & 567.74 & 1.278 & 1.078 & 1.669 \\
\hline$\# 10$ & 90 & 448.45 & 780 & 0.127 & 0.644 & 536.04 & 1.237 & 1.103 & 1.502 \\
\hline$\# \mathrm{E}$ & 100 & 549.28 & 848.48 & 0.166 & 0.706 & 638.88 & 1.044 & 0.942 & 1.546 \\
\hline
\end{tabular}

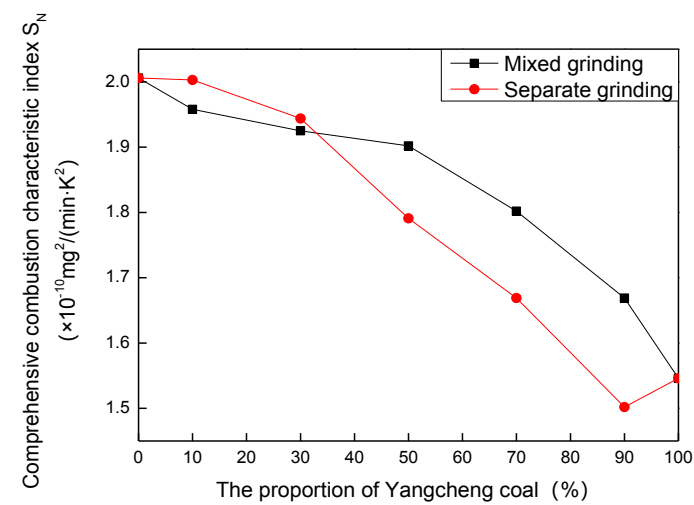

Figure 5 change trend of $\mathrm{S}_{\mathrm{N}}$ with the proportion of Yangcheng coal

\subsection{Combustion kinetics analysis}

This paper conducts the kinetics of the blended coal from ignition to burnout using the C-R method. The results are shown in Table 4.
Table 4 Dynamic parameters of combustion stage of mixed coal sample

\begin{tabular}{|c|c|c|c|c|}
\hline \multirow{2}{*}{ Sample } & $\begin{array}{l}\text { Temperature } \\
\text { range }\end{array}$ & \multirow{2}{*}{ Fitting equations } & $\begin{array}{l}\text { Activation } \\
\text { energy } \\
\text { values }\end{array}$ & $\begin{array}{l}\text { Correlation } \\
\text { coefficient }\end{array}$ \\
\hline & $\mathrm{T}\left({ }^{\circ} \mathrm{C}\right)$ & & $\begin{array}{c}E_{i} /\left(\mathrm{kJ} \cdot \mathrm{mol}^{-}\right. \\
\left.{ }^{1}\right)\end{array}$ & $\mathrm{R}^{2}$ \\
\hline$\# 1$ & $464-763$ & $\begin{array}{c}\mathrm{Y}=-8286.34 \mathrm{X}- \\
0.22814\end{array}$ & 68.89 & 0.98384 \\
\hline$\# 2$ & $459-826$ & $\begin{array}{c}\mathrm{Y}=-8634.72 \mathrm{X}- \\
4.47136\end{array}$ & 71.79 & 0.95755 \\
\hline$\# 3$ & $465-828$ & $\begin{array}{c}\mathrm{Y}=-8758.7 \mathrm{X}- \\
4.47066\end{array}$ & 72.82 & 0.96969 \\
\hline$\# 4$ & $510-884$ & $\begin{array}{c}Y=-9299.78 \mathrm{X}- \\
3.68272\end{array}$ & 77.32 & 0.97683 \\
\hline$\# 5$ & $545-897$ & $\begin{array}{c}\mathrm{Y}=-10102.4 \mathrm{X}- \\
2.90513\end{array}$ & 83.99 & 0.96584 \\
\hline$\# 6$ & $534-822$ & $\begin{array}{c}\mathrm{Y}=-7778.06 \mathrm{X}- \\
0.32095\end{array}$ & 64.67 & 0.96764 \\
\hline$\# 7$ & $466-820$ & $\begin{array}{c}\mathrm{Y}=-9448.76 \mathrm{X}- \\
3.5614\end{array}$ & 70.34 & 0.95567 \\
\hline$\# 8$ & $491-874$ & $\begin{array}{c}\mathrm{Y}=-8460.88 \mathrm{X}- \\
4.12884\end{array}$ & 76.49 & 0.95745 \\
\hline$\# 9$ & $435-688$ & $\begin{array}{c}\mathrm{Y}=- \\
9200.03 \mathrm{X}+0.8447\end{array}$ & 81.52 & 0.97932 \\
\hline$\# 10$ & $448-780$ & $\begin{array}{c}\mathrm{Y}=-10818.1 \mathrm{X}- \\
1.3366\end{array}$ & 89.94 & 0.95554 \\
\hline \#A & $549-848$ & $\begin{array}{c}\mathrm{Y}=-11685.5 \mathrm{X}- \\
2.02445\end{array}$ & 97.15 & 0.95027 \\
\hline \#E & $440-686$ & $\begin{array}{c}\mathrm{Y}=- \\
7078.32 \mathrm{X}+1.2658\end{array}$ & 58.85 & 0.97078 \\
\hline
\end{tabular}


It can be seen that for all fitting equations, $0.95<\mathrm{R}^{2}<1$, indicating a high fitting degree. The activation energy values of the blended coal during combustion is influenced by the grinding method and the proportion of Yangcheng coal. As shown in Figure 5, when the proportion of Yangcheng coal is 30\%, the activation energy values of the coals treated with two grinding methods are similar; when the proportion of Yangcheng coal is below $30 \%$, the activation energy values of the coal treated with separated grinding method is lower; when the proportion of Yangcheng coal is higher than $30 \%$, the activation energy values of the coal treated with mixed grinding method is lower. This is because the middle coal particles of the Yangcheng coal with higher hardness cannot be crushed in time; on the other hand, the crushing force is transmitted is transferred to the middle coal particles of the Zhengzhou coal with lower hardness and crushed them. At this point, the middle coal particles of Yangcheng coal acts as the crushing medium, promoting the crushing of Zhengzhou coal. Due to the friction, Yangcheng coal exerts ashear-squeeze impact on Zhengzhou coal ${ }^{[5]}$. The pulverized coal powder that are in better contact with air is more likely to react, thus lower activation energy values.

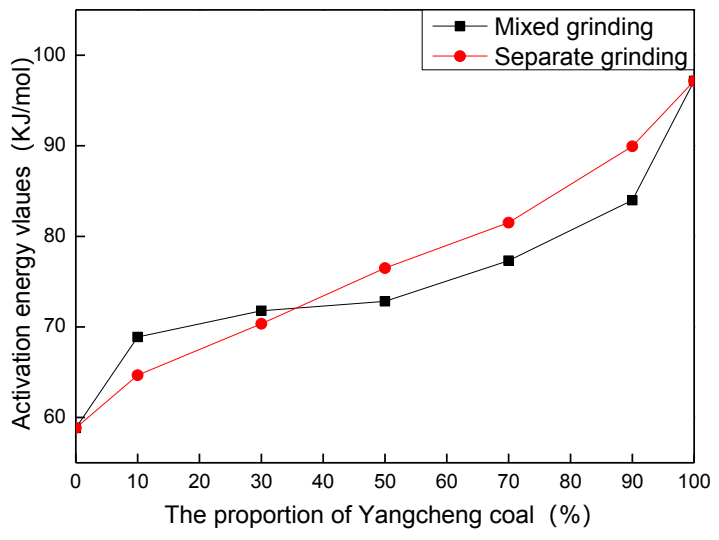

Figure 6 change trend of activation energy values with the proportion of Yangcheng coal

\section{Conclusion}

The combustion characteristic parameters of the blended coal are basically within the range of those of the two unblended coals. The comprehensive combustion characteristic index $\mathrm{S}_{\mathrm{N}}$ decreases with the increase of the proportion of Yangcheng coal. $\mathrm{S}_{\mathrm{N}}$ of the blended coal treated with the separated grinding method is basically in a linear relationship with the proportion of Yangcheng coal, while $\mathrm{S}_{\mathrm{N}}$ of the blended coal treated with the mixed grinding method is not, indicating that the mixed grinding method affects the combustion characteristics of the blended coal.

When the proportion of Yangcheng coal is $30 \%$, the combustion characteristics of the two coal grinding methods are similar; when the proportion of Yangcheng coal is less than $30 \%$, the combustion characteristics of the coal treated with separated grinding method are better; when the proportion of Yangcheng coal is higher than
$30 \%$, the combustion characteristics of the coal treated with mixed grinding method are better.

When the proportion of Yangcheng coal is $30 \%$, the activation energy values of the two coal grinding methods are similar, which indicates that the blended coal is more likely to react in the combustion area at this proportion. However, when the proportion of Yangcheng coal is less than $30 \%$, the activation energy values of the coal treated with separated grinding method is lower; when the proportion of Yangcheng coal is higher than $30 \%$, the activation energy values of the coal treated with mixed grinding method is lower.

In this experiment, as the proportion of Yangcheng coal increases, the coal with higher hardness (Yangcheng coal) will exert a more significant crushing effect on the coal with lower hardness (Zhengzhou coal). Therefore, as the proportion of Yangcheng coal increases, the mixed grinding method, which can produce particles with gradually higher fineness than the separated grinding method, will help to produce the coal with gradually better combustion characteristics.

\section{Reference}

1. CAO Yufeng, The Effect of Inner Mongolian Mixedburning Coal on 300 MW Units Operation [J]. Zhejiang Electric Power, 2014(4):34-37.

2. FU Xuanyi, MAO Dajun, YIN Qimin. Research on coal blending optimization method based on multiple algorithms in thermal power plant [J].Coal Engineering, 2018, 50(09): 150-154.

3. Wu Hao, Zou Chong, He Jiangyong 1, Wang Kai, Liu Zhanwei, Shi Shuai. Effect of low-rank coal pyrolysis conditions on combustion characteristics and kinetics of char for blast furnace injection [J/OL]. The Chinese Journal of Process Engineering:19[2019-11-01].

4. Xia Ji, Peng Peng, Hua Zhigang, Lu pan, Zhang Cheng, Chen Gang .Optimization of Pulverizers Combination for Power Plant Based on Blended Coal Combustion $[\mathrm{J}]$. Proceedings of the CSEE, 2011(29):1-8.

5. Zhang Xiaobo, Zhao Hong, YANG Jianguo. Analysis on Factors Influencing HGI and Crushing Behaviors of Blended Coals [J]. Journal of Chinese Society of Power Engineering, 2011, 31(04): 253-256+272

6. Ma Lun, Wang Tuwei, Fang Qingyan, Tan Peng, Zhang Cheng, Chen Gang. Interaction of blendedcoal combustion process:influence of coal blending methods on combustion characteristics [J]. Journal of China Coal Society,2016,41(09):2340-2346.

7. Yang Zhe. Study on the particle characteristics and combustion characteristics with different mixing way [D]. Changsha University of Science and Technology, 2013.

8. Zhu Chao. The experimental study of Porosity in the process of the blended coal combustion through different blending way [D]. Changsha University of Science and Technology,2013. 
9. Bai Haolong, Feng Qiang,Song Hua. Basic experimental analysis on mixed combustion of bituminous coal and biomass fuel[J]. Coal Processing \& Comprehensive Utilization, 2019(06): 16-19+8.

10. Wang Xiaohua ,Zhao Hongyu, Li Yuhuan, Song Qiang, Shu Xinqian .Study on releasing characteristics of pyrolysis gas products and kinetic analysis of lignite pyrolysis at different heating rates based on TG-MS [J]. Coal Engineering, 2018, 50(03): 140-144.

11. Li Guo, Zhai Ming, Wang Zhentong, et al.Comprehensive coal quality index for evaluation of coal agglomeration characteristics[J].Fuel, 2018, 231: 379-386.

12. Guo Gaofei, Liu Chaoxian, Li Bin, Zhang Ke, Wang Jing, Ou Mingyi, Lou Yuanfei, Chen Liangyuan, Zhu Wenkui. Investigation on pyrolysis/combustion characteristics and reaction kinetics of tobacco strands and tobacco powder [J]. Tobacco Science \& Technology, 2019, 52(06): 90-98.

13. Xin Shanzhi, Huang Fang, Liu Xiaoye, Xu Qingli, Mi Tie. Pyrolysis and combustion characteristics and kinetics of torrefied traditional Chinese medicine waste [J]. CIESC Journal,2019,70(08):3142-3150.

14. Du Ruiling, Wu Keng, Liu Qihang, et. Kinetics analysis of Xinglongzhuang coal pyrolysis reaction process by sectioning method [J]. Journal of Harbin Institute of Technology, 2016, 48(4): 172-176.DU R L, WU Q, LIU Q H, et al. Study on kinetics of pyrolysisreaction of Xinglongzhuang coal by segmentation method [J].Journal of Harbin Institute of Technology, 2016, 48(4): 172-176.

15. Gong Dehong, Zhang Zhongxiao, Qian Jin, Zhu Bing. Analysis of Combustion characteristics of Blended Coal under Different Pulvering Method [J]. Boiler Technology, 2017, 48(03):37-41. 